\title{
PERBANDINGAN TINGKAT PELAYANAN TERHADAP KONSUMEN INDOMARET DAN ALFAMART KAROMBASAN
}

\section{Mac Donald Walangitan}

Universitas Sam Ratulangi

\section{A R T I C L E I N F O}

Keywords :
level of service, Indomaret, Alfamart

\section{Kata Kunci :}

tingkat pelayanan, Indomaret, Alfamart

\begin{abstract}
Indomaret and Alfamart are the example of a retail business in Indonesia, which is the market leader in their field. Both companies are mini network that provides basic needs and daily necessities. But the problems faced Indomaret and Alfamart are the position of those who are always nearby.These problems is not a barrier for both. This is caused by them are in the same market share, selling products that uniform and is in the center crowds. The purpose of this study was to determine differences in the level of service to consumers and alfamart Indomaret Karombasan.

This type of research is a kind of comparative studies with different test data analysis techniques. Data obtained by distributing questionnaires at Indomaret karomabsan 100 respondents and 100 respondent's alfamart Karombasan. The results showed that there were significant differences in the quality of service to consumers Indomaret and Alfamart in Karombasan with the best service level is the level of service Indomaret Karombasan. Indomaret Karombasan must maintain the quality of service that has been applied for this so that consumers will feel comfortable and continue to make purchasing decisions in Indomaret Karombasan. Alfamart should improve the quality of service to consumers
\end{abstract}

Indomaret dan Alfamart merupakan contoh bisnis retail di Indonesia yang merupakan market leader dibidangnya. Kedua perusahaan ini merupakan jaringan minimarket yang menyediakan kebutuhan pokok dan kebutuhan sehari-hari. Namun permasalah yang dihadapi Indomaret dan Alfamart adalah posisi mereka yang selalu berdekatan. Namun permasalahan tersebut bukan menjadi penghambat bagi keduanya. Hal tersebut diakibatkan oleh mereka berada pada pangsa pasar yang sama, menjual produk yang seragam serta berada dipusat keramaian. Tujuan penelitian ini adalah untuk mengetahui perbedaan tingkat pelayanan terhadap konsumen indomaret dan alfamart karombasan.

Jenis penelitian ini adalah jenis penelitian komparatif dengan teknik analisis data uji beda. Data diperoleh dengan cara membagikan kuisioner pada 100 orang responden indomaret karomabsan dan 100 orang responden alfamart 


\section{Corresponding author :}

karombasan. Hasil penelitian menunjukkan bahwa terdapat perbedaan signifikan kualitas pelayanan terhadap konsumen Indomaret dan Alfamart di Karombasan dengan tingkat pelayanan yang paling baik adalah tingkat pelayanan Indomaret Karombasan. Indomaret Karombasan harus mempertahankan kualitas pelayanan yang sudah diterapkan selama ini agar supaya konsumen akan merasa nyaman dan terus melakukan keputusan pembelian di Indomaret Karombasan. Alfamart sebaiknya meningkatkan kualitas pelayanan terhadap konsumen

\section{PENDAHULUAN}

\section{Latar Belakang}

Persaingan bisnis retail di Indonesia menunjukan pertumbuhan yang cukup signifikan. Dikarenakan potensi pasar di Indonesia masih cukup besar dan menguatnya usaha kelas menengah dan kecil, telah menambah banyaknya kelompok masyarakat berpenghasilan menengah-atas yang memiliki gaya hidup belanja di ritel modern salah satunya adalah minimarket. Persaingan bisnis retail ini tidak terlepas dari berbagai macam strategi dan tujuan yang ingin dicapai perusahaan tersebut, beberapa tujuan yang biasanya ditetapkan adalah maksimalisasi penjualan, maksimalisasi keuntungan, maksimalisasi pengembalian investasi dan minimalisasi biaya.Perusahaan pada dasarnya menjual produk-produknya dihadapkan dengan strategi maupun teknik penjualan yang bagus, sehingga komoditas yang ditawarkannya dapat terjual dengan baik. Salah satu teknik penjualan yang dimaksud adalah terkait dengan bagaimana dan seberapa baik kualitas pelayanan yang diberikan terhadap konsumen.

Indomaret dan Alfamart merupakan contoh bisnis retail di Indonesia yang merupakan market leader dibidangnya. Kedua perusahaan ini merupakan jaringan minimarket yang menyediakan kebutuhan pokok dan kebutuhan sehari-hari. Namun permasalah yang dihadapi Indomaret dan Alfamart adalah posisi mereka yang selalu berdekatan.namun permasalahan tersebut bukan menjadi penghambat bagi keduanya. Hal tersebut diakibatkan oleh mereka berada pada pangsa pasar yang sama, menjual produk yang seragam serta berada dipusat keramaian.

Kualitas pelayanan yang diberikan adalah merupakan kinerja terpenting oleh perusahaan bagi kepuasan konsumen atau pelanggan. Perusahaan harus memperhatikan hal-hal penting bagi konsumen, agar mereka merasakan kepuasan sebagaimana yang diharapkan. Masalah pelayanan sebenarnya bukanlah hal yang sulit, tetapi jika hal ini kurang diperhatikan maka dapat menimbulkan hal-hal yang tidak baik dikarenakan sifatnya yang sensitif. Sistem pelayanan perlu didukung oleh kualitas pelayanan, fasilitas yang memadai dan etika atau tata krama. Untuk tujuan pelayanan adalah untuk memberikan kepuasan kepada konsumen, sehingga berakibat dengan dihasilkannya nilai tambah bagi perusahaan.

Berdasarkan uraian tersebut maka focus penelitian ini adalah untuk membandingkan tingkat pelayanan terhadap konsumen Indomaret dan Alfamart

\section{Tujuan Penelitian}

Berdasarkan latar belakang masalah diatas maka tujuan penelitian ini untuk mengetahui perbandingan tingkat pelayanan terhadap konsumen indomaret dan alfamart karombasan. 


\section{TINJAUAN PUSTAKA}

\section{Manajemen Pemasaran}

Pemasaran adalah proses sosial dan manajerial dimana individu dan kelompok memperoleh apa yang mereka ingin dan butuhka melalui penciptaan dan pertukaran barang dan nilai dengan pihak lain (Kotler dan Armstrong, 2004). Manajemen pemasaran adalah analisis, perencanaan, penerapan, dan pengendalian programprogram yang dirancang untuk menciptakan, membangun, dan mempertahankan pertukaran yang saling menguntungkan dengan pembeli sasaran dalam rangka mencapai tujuan organisasi. Proses itu melibatkan lebih dari sekedar mendapat cukup pelanggan bagi output perusahaan saat ini. Lebih dari sekedar merancang strategi untuk menarik konsumen baru dan menciptakan transaksi dengan mereka, perusahaan sekarang ini berfokus pada mempertahankan pelanggan saat ini dan membangun hubungan jangka panjang melalui penawaran nilai dan kepuasan yang unggul bagi pelanggan.

\section{Perilaku Konsumen}

Sciffman dan Kanuk dalam Sumarwan (2003:25) mendefinisikan bahwa perilaku konsumen sebagai perilaku yang diperlihatkan konsumen dalam mencari, membeli, menggunakan, mengevaluasi dan menghabiskan produk dan jasa yang mereka harapkan akan memuaskan kebutuhan mereka. Pemahaman akan perilaku konsumen dapat diaplikasikan dalam beberapa hal, yang pertama adalah untuk merancang sebuah strategi pemasaran yang baik. Kedua, perilaku konsumen dapat membantu pembuat keputusan membuat kebijakan publik. Ketiga adalah dalam hal pemasaran sosial (social marketing), yaitu penyebaran ide di antara konsumen.

\section{Retail}

Menurut Levy dan Weitz (2001:8) "Retailing adalah satu rangkaian aktivitas bisnis untuk menambah nilai guna barang dan jasa yang dijual kepada konsumen untuk konsumsi pribadi atau rumah tangga”. Jadi konsumen yang menjadi sasaran dari retailing adalah konsumen akhir yang membeli produk untuk dikonsumsi sendiri. Dalam memilih retail store, pembeli mempertimbangkan banyak hal. Faktor yang diperhatikan adalah yang berkaitan dengan kebutuhan ekonominya. Di lain pihak kebutuhan emosional (seperti gengsi) juga kadangkala mempengaruhi pilihannya.

\section{Kualitas Pelayanan}

Menurut Sutedja (2007:5) pelayanan atau servis dapat diartikan sebagai sebuah kegiatan atau keuntungan yang dapat ditawarkan oleh satu pihak kepada pihak lain. Pelayanan tersebut meliputi kecepatan melayani, kenyamanan yang diberikan, kemudahan lokasi, harga wajar dan bersaing Ciri-ciri pelayanan yang baik menurut Kasmir (2005:39) sebagai berikut:

1. Bertanggung jawab kepada setiap pelanggan/pengunjung sejak awal hingga selesai.

2. Mampu melayani secara cepat dan tepat.

3. Mampu berkomunikas.

4. Mampu memberikan jaminan kerahasiaan setiap transaksi.

5. Memiliki pengetahuan dan kemampuan yang baik.

6. Berusaha memahami kebutuhan pelanggan/pengunjung.

7. Mampu memberikan kepercayaan kepada pelanggan/pengunjung. 


\section{Penelitian Terdahulu}

1. Nel Arianty (2013) meneliti analisis perbedaan pasar modern dan pasar tradisional ditinjau dari strategi tata letak (lay out) dan kualitas pelayanan untuk meningkatkan posisi tawar pasar tradisional. Penelitian ini menggunakan pendekatan penelitian deskriptif kuantitatif serta uji perbedaan persepsi konsumen terhadap pasar modern dan pasar tradisional dari segi tata letak dan kualitas pelayanan. Hasil uji perbedaan persepsi konsumen dari segi tata letak menunjukkan ada perbedaan signifikan dengan nilai bahwa nilai probabilitas t (Sig2tailed ) sebesar 0.000 [ Sig (2tailed) $\leq \alpha 0.05$ ]. Dari uji perbedaan persepsi konsumen dari segi kualitas pelayanan, terlihat bahwa nilai probabilitas t (Sig2tailed ) sebesar 0.000[ Sig (2tailed) $\leq \alpha 0.05$ ], yang berarti ada perbedaan yang signifikan antara kualitas pelayanan pasar moden dan pasar tradisional.

2. Subarsono, Heriyono dan Tohidi (2014) meneliti tentang perbedaan pelayanan pada ritel tradisional dengan ritel modern di kota cirebon. Pertumbuhan perekonomian masyarakat diikuti dengan pertumbuhan bisnis ritel yang semakin pesat. Indonesia dengan jumlah penduduk ke-empat terbanyak di dunia setelah Cina dan India memiliki potensi yang sangat besar bagi pasar ritel. Salah satu jenis pasar modern yang saat ini sedang berkembang pesat menawarkan kemudian karena lokasi toko atau gerai yang dekat dengan konsumen serta mengutamakan kepraktisan dan kecepatan atau waktu yang tidak lama dalam berbelanja. Ritel mempunyai arti penjualan secara eceran. Seiring tuntutan pasar bebas, ritelpun belakangan bertambah dengan konsep ritel modern. Ritel tradisional merupakan ritel sederhana dengan tempat yang tidak terlalu luas, barang yang dijual terbatas jenisnya. Sistem menajemen yang sederhana memungkinkan adanya proses tawar menawar harga. Pengujian Hipotesis ; Analisa terdapat atau tidak terdapatnya perbedaan digunakan rumus uji t Separated Variance. Hasil perhitungan t hitung lebih besar daripada t tabel; maka hipotesis yang menyatakan terdapat perbedaan pelayanan antara ritel tradisional dengan ritel modern diterima

\section{Kerangka Konseptual}

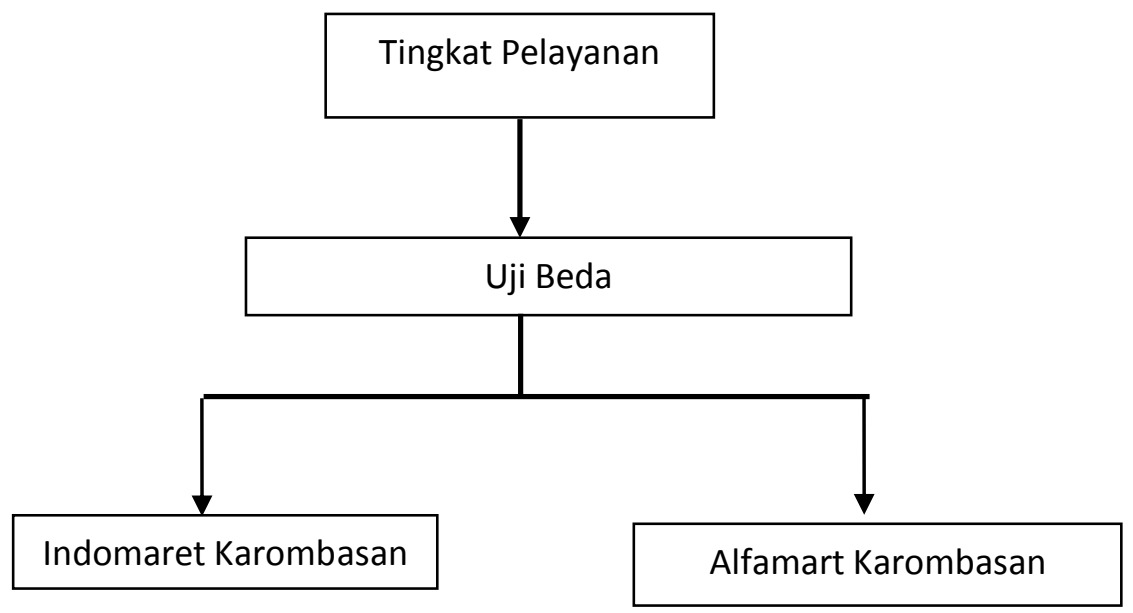

Gambar 1. Kerangka Penelitian

\section{Hipotesis Penelitian}

Diduga terdapat perbedaan signifikan tingkat pelayanan terhadap Konsumen Indomaret dan Alfamart Karombasan 


\section{METODE PENELITIAN}

\section{Jenis Penelitian}

Penelitian ini merupakan penelitian komparatif. Penelitian komparatif adalah jenis penelitian yang digunakan untuk membandingkan antara dua kelompok atau lebih dari suatu variabel tertentu. (Sugiyono, 2012). Dalam penelitian ini komparasi yang dimaksud adalah perbandingan tingkat pelayanan terhadap konsumen Indomaret dan Alfamart Karombasan.

\section{Tempat dan Waktu Penelitian}

Penelitian ini mengambil tempat pada Indomaret Karombasan dan Alfamart Karombasan dengan waktu penelitian selama 3 bulan.

\section{Populasi dan Sampel}

Populasi memiliki pengertian sebagai seluruh kumpulan elemen yang menunjukkan ciri-ciri tertentu yang dapat digunakan untuk membuat kesimpulan. Adapun yang menjadi populasi dalam penelitian ini adalah seluruh konsumen Indomaret dan Alfamart di Karombasan. Sampel adalah bagian dari populasi yang diambil/ditentukan berdasarkan karakteristik dan terknik tertentu. Sampel dalam penelitian ini berjumlah 100 responden (100 Responden yaitu Konsumen Indomaret dan 100 Responden Konsumen Alfamat)

\section{Metode Analisis}

Metode analisa yang digunakan adalah uji beda yaitu perbandingan tingkat pelayanan terhadap konsumen Indomaret dan Alfamart di Karombasan. Namun sebelumnya kuisioner penelitian diuji dengan menggunakan uji valid dan uji reliable.

\section{Uji Validitas}

Uji Validitas digunakan untuk mengukur valid atau tidaknya suatu kuesioner. Analisis dimulai dengan membandingkan nilai signifikansi dengan alpha $(0,05)$. Jika nilai signifikansi $<0,05$ maka kuisioner dinyatakan valid . (Ghozali 2009)

\section{Uji Reliabilitas}

Uji reliabilitas digunakan untuk mengetahui sejauh mana suatu alat pengukur dapat dipercaya atau dapat diandalkan dan tetap konsisten jika dilakukan dua kali pengukuran atau lebih pada kelompok yang sama dengan alat ukur yang sama. Jika nilai cronbach alpha > 0,6 maka kuisioner dinyatakan reliable. (Ghozali 2009)

\section{Uji Beda}

Uji beda dilakukan untuk mengetahui apakah dua populasi yang kita pelajari itu mempunyai rata-rata yg perbedaanya tidak berarti, arau apakah terdapat perbedaan yang cukup memberikan keyakinan kepada kita untuk menyimpulkan bahwa dua sampel yang kita ambil itu berasal dari populasi dengan rata-rata yang tidak sama. (Sugiyono, 2012). Keriteria Uji beda Menentukan taraf signifikansi. Uji hipotesis menggunakan uji dua pihak ( $t w o$ tail test) dengan taraf Signifikansi 5\%. Dalam hal ini bila peluang kesalaha 5\% maka taraf kepercayaannya $95 \%$. Artinya kesalahan pengambilan keputusan dalam menolak hipotesis yang benar adalah maksimal 5\%. Untuk 
mengetahui nilai $\mathrm{t}$ tabel digunakan tabel distribusi $\mathrm{t}$ dengan $5 \%: 2=2,5 \%$ (two tail) dengan derajat kebebasan (dk)

$=\mathrm{n} 1+\mathrm{n} 2-$ Pengambilan keputusan. Dengan membandingkan nilai thitung dengan nilai $\mathrm{t}$ tabel :

- Jika nilai t hitung $\geq$ nilai $t$ tabel maka H0 ditolak

- Jika nilai t hitung < nilai t tabel maka H0 diterima

Dengan melihat nilai probabilitas signifikansi :

- Probabilitas signifikansi >0,05, maka H0 diterima

- Probabilitas signifikansi < 0,05, maka H0 ditolak

\section{Pengukuran Variabel}

Variabel tingkat pelayanan diukur dengan indikator sebagai berikut :

1. Tangible

Tangible merujuk pada fasilitas fisik, peralatan, dan penampilan dari para personil.

2. Reliability

Relibility merujuk pada kemampuan untuk menghantarkan layanan sesuai seperti yang telah dijanjikan tanpa suatu kesalahan (konsisten) serta akurat.

3. Responsiveness

Responsiveness merujuk pada kemauan untuk menolong para pelanggan dan menyediakan suatu layanan dengan segera/tepat waktu.

4. Assurance

Assurance merujuk pada pengetahuan (knowledge) dan kesopanan dari para karyawan serta kemampuan mereka untuk menimbulkan rasa percaya (trust) dan yakin

5. Emphaty.

Emphaty merujuk pada sejauh mana tingkat pemahaman/simpati (caring) serta perhatian secara individual yang diberikan oleh perusahaan kepada para pelanggannya.

Dalam melakukan pengukuran atas jawaban dari kuesioner-kuesioner tersebut diajukan kepada responden, skala yang digunakan adalah skala Likert. Berikut adalah skor untuk setiap jawaban skala likert :

Tabel 1. Skor untuk jawaban skala likert

\begin{tabular}{ccc}
\hline No & Keterangan & Skor \\
\hline 1 & Sangat Setuju & 5 \\
2 & Setuju & 4 \\
3 & Ragu-ragu & 3 \\
4 & Tidak Setuju & 2 \\
5 & Sangat Tidak Setuju & 1 \\
\hline
\end{tabular}

Sugiyono (2012:93) 


\section{HASIL PENELITIAN DAN PEMBAHASAN}

\section{Hasil Penelitian}

\section{Deskripsi Responden Indomaret dan Alfamart}

Berikut ini adalah deskripsi responden Indomaret dan Alfamart berdasarkan Jenis Kelamin, Tingkat Pendapatan dan usia.

\section{Tabel 2. Responden Berdasarkan Jenis Kelamin}

\begin{tabular}{cccccc}
\hline \multirow{2}{*}{ No } & \multirow{2}{*}{ Jenis Kelamin } & \multicolumn{2}{c}{ Indomaret } & \multicolumn{2}{c}{ Alfamart } \\
\cline { 3 - 6 } & & Jumlah & Persentase & Jumlah & Persentase \\
\hline 1 & Laki-laki & 52 & 52 & 61 & 61 \\
2 & Perempuan & 48 & 32 & 39 & 32 \\
\hline & Total & 100 & 100 & 100 & 100
\end{tabular}

Sumber : Data hasil kuisioner, 2017

Tabel 2 menunjukkan responden berdasarkan jenis kelamin. Jumlah responden laki-laki di Indomaret adalah sebanyak 52 orang dan untuk Alfamart adalah sebanyak 61 orang.

Tabel 3. Responden Berdasarkan Pendapatan

\begin{tabular}{cccccc}
\hline \multirow{2}{*}{ No } & \multirow{2}{*}{ Pendapatan } & \multicolumn{2}{c}{ Indomaret } & \multicolumn{2}{c}{ Alfamart } \\
\cline { 3 - 6 } & & Jumlah & Persentase & Jumlah & Persentase \\
\hline 1 & $<$ Rp 1.000.000 & 38 & 38 & 43 & 43 \\
2 & Rp 1.000.000-1.500.000 & 26 & 26 & 21 & 21 \\
3 & Rp 1.500.000-5.000.000 & 24 & 24 & 19 & 19 \\
4 & $>$ Rp 5.000.000 & 12 & 12 & 17 & 17 \\
\hline \multicolumn{2}{c}{ Total } & 100 & 100 & 100 & 100 \\
\hline
\end{tabular}

Sumber : Data hasil kuisioner, 2017

Tabel 3 menunjukkan responden berdasarkan pendapatan. Jumlah responden yang berpendapatan < Rp 1.000.000 untuk Indomaret adalah sebanyak 38 orang dan pada Alfamart sebanyak 43 orang yang merupakan kelompok responden terbanyak. Sementara responden terendah berada pada tingkat pendapatan > Rp 5.000.000 yaitu pada Indomaret adalah sebanyak 12 orang dan pada Alfamart sebanyak 17 orang.

\section{Tabel 4. Responden Berdasarkan Usia}




\begin{tabular}{lccccc}
\hline \hline \multirow{2}{*}{ No } & Pendapatan & \multicolumn{2}{c}{ Indomaret } & \multicolumn{2}{c}{ Alfamart } \\
\cline { 3 - 6 } & & Jumlah & Persentase & Jumlah & Persentase \\
\hline 1 & $<17$ Tahun & 18 & 18 & 21 & 21 \\
2 & 18-25 Tahun & 25 & 25 & 29 & 29 \\
3 & 26- 40 Tahun & 37 & 37 & 28 & 28 \\
4 & $>$ 40 Tahun & 20 & 20 & 22 & 22 \\
\hline & Total & 100 & 100 & 100 & 100 \\
\hline
\end{tabular}

Sumber : Data hasil kuisioner, 2017

Tabel 4 menunjukkan responden berdasarkan usia. Jumlah responden yang < 17 tahun untuk Indomaret adalah sebanyak 18 orang dan pada Alfamart sebanyak 21 orang yang merupakan kelompok responden paling sedikit. Sementara responden tertinggi berada 26-40 tahun yaitu pada Indomaret adalah sebanyak 37 orang dan pada Alfamart sebanyak 29 orang.

\section{Uji Validitas dan Reliabilitas Kuisioner}

Tabel 5. Uji validitas dan Reliabilitas Kuisioner

\begin{tabular}{cccccc}
\hline Variabel & Pernyataan & Sig & Status & $\begin{array}{c}\text { Cronbach } \\
\text { Alpha }\end{array}$ & Status \\
\hline Tingkat Pelayanan Indomaret & 1 & 0,000 & Valid & 0,728 & Reliabel \\
& 2 & 0,000 & Valid & & Reliabel \\
& 3 & 0,000 & Valid & & Reliabel \\
Tingkat Pelayanan Alfamart & 4 & 0,000 & Valid & & Reliabel \\
& 5 & 0,000 & Valid & & Reliabel \\
& 1 & 0,000 & Valid & 0,727 & Reliabel \\
& 2 & 0,000 & Valid & & Reliabel \\
& 3 & 0,000 & Valid & & Reliabel \\
& 4 & 0,000 & Valid & & Reliabel \\
& 5 & 0,000 & Valid & & Reliabel \\
\hline
\end{tabular}

Sumber : Olah Data SPSS 20, 2017

Tabel 5 menunjukkan bahwa nilai signifikan untuk setiap pernyataan adalah < alpha yaitu 0,05 maka dapat disimpulkan bahwa setiap pernyataan dikatanan valid. Nilai alpha cronbach untuk setiap pernyataan > 0,6 maka dapat disimpulkan bahwa setiap pernyataan dikatakan reliable. 


\section{Analisis Deskriptif}

Tabel 6. Analisis Deskriptif

\begin{tabular}{cccc}
\hline Variabel & Mean & N & $\begin{array}{c}\text { Std. } \\
\text { Deviation }\end{array}$ \\
\hline Tingkat Pelayanan Indomaret & 20.3800 & 100 & 2.21920 \\
Tingkat Pelayanan Alfamart & 19.6600 & 100 & 2.04604
\end{tabular}

Sumber : Olah Data SPSS 20, 2017

Tabel 6 menunjukkan nilai rata-rata untuk tingkat pelayanan Indomaret adalah sebesar 20,38 dan tingkat pelayanan Alfamart adalah sebesar 19,66. Hal tersebut menandahkan bahwa tingkat pelayanan indomaret lebih baik dari alfamart

\section{Uji Beda}

Tabel 7.Uji Beda

\begin{tabular}{|c|c|c|c|c|c|}
\hline Perbandingan & Mean & $\begin{array}{c}\text { Std. } \\
\text { Deviation }\end{array}$ & $\mathrm{t}$ & df & $\begin{array}{l}\text { Sig. (2- } \\
\text { tailed) }\end{array}$ \\
\hline $\begin{array}{l}\text { Tingkat Pelayanan Indomaret - Tingkat Pelayanan } \\
\text { Alfamart }\end{array}$ & .72000 & 3.05201 & 2.359 & 99 & .020 \\
\hline
\end{tabular}

Sumber : Olah Data SPSS 20, 2017

Tabel menunjukkan uji beda untuk tingkat pelayanan Indomaret dan alfamart. Nilai signifikansi sebesar $0,020<0,05$ yang berarti $\mathrm{H}_{0}$ ditolak dan $\mathrm{H}_{\mathrm{a}}$ diterima yang berarti terdapat perbedaan signifikan kualitas pelayanan terhadap konsumen Indomaret dan Alfamart di Karobasan.

\section{Pembahasan}

Kualitas pelayanan terpusat pada upaya pada pemenuhan kebutuhan dan keinginan konsumen. Kualitas pelayanan merupakan ukuran penilaian menyeluruh atas tingkat suatu pelayanan yang baik. Kualitas pelayanan sebagai hasil persepsi dari perbandingan antara harapan pelanggan dengan kinerja actual pelayanan. Kualitas pelayanan ditentukan oleh bagaimana tingkat kesesuaian antara pelayanan yang diberikan dengan pelayanan yang diharapkan pelanggan. semakin tinggi kualitas pelayanan yang dirasakan akan semakin tinggi tingkat kepuasan pelanggan. Selanjutnya semakin berdampak positif pada niat pembelian konsumen. Beberapa studi mengemukakan bahwa kualitas pelayanan memiliki hubungan yang erat dengan kepuasan pelanggan. Kualitas pelayanan mempengaruhi kepuasan pelanggan dan pada akhirnya berpengaruh terhadap loyalitas pelanggan

Hasil penelitian menunjukkan bahwa Terdapat perbedaan signifikan kualitas pelayanan terhadap konsumen Indomaret dan Alfamart di Karobasan. Perbedaan secara signifikan tersebut berarti terdapat perbedaan yang jauh. Hal tersebut diakibatkan oleh respon yang tinggi, reliabilitas, jaminan yang baik dari karyawan indomaret terhadap 
konsumennya. Hasil penelitian ini didukung oleh penelitian Nel Arianty (2013) yang menemukan bahwa terdapat perbedaan signifikan kualitas pelayanan pasar modern dan pasar tradisional.

\section{PENUTUP}

\section{Kesimpulan}

Kesimpulan penelitian ini sebagai berikut :

1. Terdapat perbedaan signifikan kualitas pelayanan terhadap konsumen Indomaret dan Alfamart di Karombasan

2. Tingkat pelayanan indomaret lebih baik dari tingkat pelayanan alfamart

\section{Saran}

Saran yang dapat diberikan sebagai berikut :

1. Indomaret Karombasan harus mempertahankan kualitas pelayanan yang sudah diterapkan selama ini agar supaya konsumen akan merasa nyaman dan terus melakukan keputusan pembelian di Indomaret Karombasan

2. Alfamart sebaiknya meningkatkan kualitas pelayanan terhadap konsumen

\section{DAFTAR PUSTAKA}

Ghozali, Imam. (2009). Aplikasi Analisis Multivariate Dengan Program SPSS, Edisi Keempat, Penerbit Universitas Diponegoro.

Kasmir.(2005). Etika Customer Service. Raja Grafindo Persada. Jakarta.

Kotler dan Amstrong. (2004). Prinsip-prinsip Marketing, Edisi Ketujuh, Jakarta:Penerbit Salemba Empat.

Levy \& Weitz. (2001). Retailing Management, $4^{\text {th }}$ edition. New York: Mc.Graw Hill, Irwin.

Nel arianty. (2013). Analisis Perbedaan Pasar Modern Dan Pasar Tradisional Ditinjau Dari Strategi Tata Letak (Lay Out) Dan Kualitas Pelayanan Untuk Meningkatkan Posisi Tawar Pasar Tradisional. jurnal.umsu.ac.id. index.php/mbisnis/article/download/106/pdf_6. Diakses tanggal 12 Desember 2016.

Subarsono, Heriyono dan Tohidi. 2014. Perbedaan Pelayanan Pada Ritel Tradisional Dengan Ritel Modern Di Kota Cirebon. cdc.untagcirebon.ac.id/download.php?. Diakses tanggal 12 Desember 2016.

Sugiyono. (2012). Metode Penelitian Kuantitatif Kualitatif dan R\&B. Bandung: Alfabeta.

Sutedja, Wira. (2007). Panduan Layanan Konsumen. Jakarta: PT. Grasindo.

Sumarwan, Ujang. (2003). Perilaku Konsumen. Jakarta: Penerbit GhaliaIndonesia. 